\title{
Uma análise do argumento do Conjunto Defeituoso de van Fraassen e seu impacto no Realismo Científico
}

\author{
An analysis of the Van Fraassen's Bad Lot argument and its impact on \\ scientific realism
}

\author{
GABRIEL CHIAROTTI SARDI ${ }^{1}$
}

\begin{abstract}
Resumo: Ao longo do debate em torno do realismo científico, os adeptos de tal vertente filosófica buscaram inúmeras vezes fundamentar sua posição através do famoso argumento da Inferência da Melhor Explicação (Inference to the Best Explanation - IBE), o qual se propõe como um reflexo da prática inferencial científica através da eliminação de hipóteses rivais. Bas van Fraassen (1989) elaborou uma crítica a essa defesa, com o assim denominado Argumento do Conjunto Defeituoso ( $B a d$ Lot), no qual o autor questiona a possibilidade de IBE esgotar todas as possíveis alternativas de comparação, pois a hipótese adotada pode ser a melhor de um conjunto defeituoso avaliado. Os realistas objetaram ao argumento, primeiramente, alegando que a posição empirista de van Fraassen sofre as mesmas consequências que a posição realista e, sobretudo, que tal argumento não tem relação com a prática científica real, não sendo mais do que uma objeção de cunho lógico e abstrato, por não considerar o conhecimento anterior consolidado. $O$ presente artigo visa, em um primeiro momento, a reconstrução dos argumentos da IBE e Bad Lot, bem como suas críticas, mostrando suas lacunas e indicando que uma possível solução seja um estudo minucioso do conceito de conhecimento anterior.
\end{abstract}

Palavras-chave: Bas van Fraassen. Realismo/Antirrealismo Científico. Bad Lot.

Abstract: Along the discussion around the scientific realism, adepts of such philosophical strand have repeatedly sought to justify their position through the famous Inference to the Best Explanation (IBE) argument, which is proposed as a reflection of practice scientific inferential through the elimination of rival hypotheses. Bas van Fraassen (1989) developed a critique of this defense, with the so-called Bad Lot argument, in which the author questions the possibility of IBE exhausting all possible alternatives for comparison, because the hypothesis adopted may be the best of a bad lot evaluated. The realists objected to the argument, first, claiming that van Fraassen's empiricist position suffers the same consequences as the realistic position and, above all, that such an argument has no relation to real scientific practice, being nothing more than a logical and abstract objection, for not considering the previous consolidated knowledge. This article aims, at first, to reconstruct the arguments of IBE and Bad Lot, as well as their criticisms, showing their gaps and indicating that a possible solution is a thorough study of the concept of background knowledge.

Keywords: Bas van Fraassen. Scientific Realism/Anti-realism. Bad Lot.

\section{Introdução}

Desde meados das décadas de $1970-80$ até os dias atuais, há no círculo acadêmico de filosofia da ciência um debate que ficou conhecido como realismo $x$

\footnotetext{
1 Graduando em Filosofia pela Universidade Estadual de Londrina (UEL), IC/CNPq. E-mail: gabrielchi@hotmail.com
} 
antirrealismo científico ${ }^{2}$; onde a questão central trata da avaliação de nossas teorias científicas ao que tange uma representação exata do mundo externo e a existência de leis e entidades (observáveis e, sobretudo, inobserváveis ${ }^{3}$ ) independentemente da nossa consciência. A questão se trava de um modo geral, sobre a atitude epistêmica que devemos ter diante das nossas melhores teorias científicas e inúmeros argumentos foram levantados para defender tanto posições realistas quanto antirrealistas.

O argumento da Inferência da Melhor Explicação se tornou uma das defesas mais sofisticadas e importantes para os adeptos do realismo científico, pois se propõe como um reflexo da prática inferencial científica através da eliminação de hipóteses rivais. Contudo, filósofos antirrealistas, como, por exemplo, Bas van Fraassen, buscaram mostrar a existência de problemas ao se adotar IBE como uma justificativa plausível de crença nos enunciados do realismo científico, Em 1989, van Fraassen elaborou uma crítica que ficou conhecida como o Argumento do Conjunto Defeituoso (Bad Lot), no qual o autor questiona a possibilidade de IBE esgotar todas as possíveis alternativas de comparação, pois a hipótese adotada pode ser a melhor de um conjunto defeituoso avaliado.

Os realistas objetaram ao argumento de van Fraassen primeiramente alegando que a sua posição empirista sofre as mesmas consequências que a posição realista e, sobretudo que tal argumento não tem relação com a prática científica real, não sendo mais do que uma objeção de cunho lógico e abstrato por não considerar o conhecimento anterior consolidado. $O$ presente artigo visa em um primeiro momento a reconstrução dos argumentos da IBE e Bad Lot, bem como suas críticas, demonstrando suas lacunas e indicando que uma possível solução seja um estudo minucioso do conceito de conhecimento anterior, partindo de uma abordagem socioconstrutivista.

\section{1 - Realismo, Antirrealismo e a Inferência da Melhor Explicação}

\footnotetext{
${ }^{2}$ Embora possamos encontrar um início precursor da discussão na obra De Motu (1721), de autoria de George Berkeley, onde o filósofo defende uma concepção filosófica conhecida como instrumentalismo, na qual o escopo da prática científica é somente fornecer teorias que são empiricamente adequadas, de modo que estas teorias forneçam predições observacionais bemsucedidas (NEWTON-SMITH, 1985), sendo tanto as teorias quanto as entidades inobserváveis postuladas por elas interpretadas como instrumentos, dadas suas capacidades explicativas e preditivas (BERKELEY, 2006, p. 119).

${ }^{3}$ Entidades observáveis são os componentes de uma teoria científica passíveis de observação empírica, como, por exemplo, as luas de Júpiter. Já por sua vez, entidades inobserváveis são os componentes de uma teoria científica que não são passíveis de observação empírica direta, mas são postulados por desempenhar um papel-chave dentro da rede conceitual da teoria, permitindo que a mesma seja bem-sucedida, como, por exemplo, os elétrons. Uma interessante distinção entre entidades observáveis e inobserváveis - sobretudo quando se faz necessária a utilização de instrumentos tecnológicos para que seja possível a observação - pode ser encontrada na obra $A$ Imagem Científica de Bas van Fraassen (2007, p.41).
} 
Se o objeto do debate é a própria ciência e a atitude epistêmica que devemos ter diante dela, então primeiramente devemos ter em mente que uma teoria científica é o produto de uma atividade humana que podemos livremente denominar de prática científica, e essa, por sua vez, pode possuir motivações externas variadas, sejam elas: militares, econômicas, políticas, etc.; porém, seu objetivo interno, intrínseco, é a formulação de explicações sólidas das causas de fenômenos e de meios de predições destes, sendo esta uma das metas prioritárias dos cientistas, opinião na qual grande parte dos filósofos da ciência está de acordo (GHINS, 2013, p. 15).

O Realismo Científico é a posição epistêmica que assume o pressuposto de que as nossas melhores teorias científicas "nos dizem como o mundo é, tanto em seus aspectos observáveis quanto inobserváveis" (FRENCH, 2009, p. 92). Sua motivação filosófica tem origem no sucesso das ciências naturais (SILVA; MINIKOSKI, 2016 p. 236) e por este mesmo sucesso os realistas cientificos postulam que a atitude de um cientista perante uma teoria bem-sucedida deve ser a de aceitação na crença de sua verdade e da aceitação da existência de suas entidades inobserváveis inferidas, pois, caso contrário, o sucesso seria mera coincidência (SOUZA, 2015, p. 114) ${ }^{4}$. Portanto para o filósofo realista de um modo geral, nossas teorias científicas podem ser verdadeiras ou falsas ${ }^{5}$ se a mesma for respectivamente bem ou malsucedida. Segundo Steven French para o realista as teorias científicas compreendem três aspectos fundamentais: "A) são verdadeiras; B) descrevem corretamente que tipos de coisas há no mundo (observáveis e inobserváveis); C) descrevem corretamente a maneira como essas coisas estão relacionadas" (FRENCH, 2009, p. 94).

Já o Antirrealismo Científico por sua vez, é a postura na qual se interpreta as teorias científicas não como passíveis de exprimir verdades objetivas, mas sim como constructos mentais que buscam representar a realidade e prever fenômenos, via de regra, através da adequação empírica entre teoria-fenômeno. Basicamente o antirrealista assume o pressuposto de que o nosso conhecimento científico acerca da realidade é limitado por nossas faculdades de observação (OKASHA, 2002, p. 61), portanto entidades inobserváveis podem ser aceitas, conquanto haja demarcações epistêmicas à sua valoração e as teorias científicas até podem ser verdadeiras, mas estamos impossibilitados de afirmar isso com total certeza. Um ponto fundamental é estarmos conscientes que um filósofo antirrealista não desvaloriza a prática científica ou muito menos ignora seus enunciados, pelo contrário, ele a considera fundamental para o conhecimento humano tal como o realista também o faz; no

\footnotetext{
${ }^{4}$ Este é o famoso Argumento do Milagre ou Argumento Sem Milagres do renomado filósofo Hilary Putnam. "O argumento positivo para o realismo consiste em que ele é a única filosofia que não faz do sucesso da ciência um milagre" (PUTNAM, 1979).

${ }^{5}$ Para um filósofo antirrealista, como, por exemplo, Bas van Fraassen, nossas teorias podem sim ser verdadeiras ou falsas, porém nossa capacidade de avaliação de seu real valor epistêmico é limitada. Neste sentido, van Fraassen é um realista semântico, mas não um realista epistêmico (BUENO, 1999, p. 115; Psillos, 1999, p. 77).
} 
entanto o antirrealista lhe restringe limitações epistemológicas para sua interpretação e aceitação.

Embora a perspectiva realista em um primeiro momento aparente ser a mais coerente por estar de acordo com o senso-comum, ela pode se mostrar muito problemática quando são levantadas pelos antirrealistas algumas objeções, sejam elas de caráter relativista ou historiográfico, como o argumento da meta-indução pessimista $^{6}$ (LAUDAN, 1981); ou ainda de ordem epistêmico-metodológica, tal como o problema da subdeterminação da teoria pelos dados ${ }^{7}$, que pode ser encontrado nos trabalhos de Quine.

No entanto, um dos mais célebres argumentos usados em defesa do realismo científico é o argumento da Inferência da Melhor Explicação (Inference to the Best Explanation), apresentado sem intenções realistas (SILVA; MINIKOSKI, 2016, p. 238) por Gilbert Harman em $1965^{8}$ :

Ao se construir [a inferência da melhor explicação] se infere, do fato de que certa hipótese explicaria a evidência, a verdade desta hipótese. Em geral existem diversas hipóteses que poderiam explicar a evidência, de modo que deve ser capaz de rejeitar todas tais hipóteses alternativas antes de se estar seguro em fazer a inferência. Assim se infere, da premissa de que uma dada hipótese forneceria uma explicação "melhor" para a evidência do que quaisquer outras hipóteses, a conclusão de que esta determinada hipótese é verdadeira. (HARMAN, 1965, p. 89)

A partir da formulação de Harman, podemos formatar o argumento da seguinte maneira (SILVA, 2011, p. 274):

1) uma evidência E deve ser explicada;

2) a hipótese $\mathrm{H}$ explica melhor E do que outras hipóteses rivais;

3) conclusão: $H$ é passível de crença em sua verdade.

Harman salienta a importância da utilização da inferência da melhor explicação dentro da prática científica e, além disso, busca legitimar o processo inferencial do cientista ao postular entidades inobserváveis (SILVA, 2011, p. 274): "Quando um cientista infere a existência de átomos e partículas subatômicas, ele

\footnotetext{
${ }^{6}$ Basicamente o argumento da "meta-indução pessimista" (the pessimist meta-induction) propõe o seguinte raciocínio: se os entes inobserváveis postulados por teorias do passado que foram abandonadas (como o flogisto da Química ou o éter da Física) não existem, possivelmente os entes inobserváveis de nossas teorias atuais também podem não existir (DEVITT, 2008, p. 232).

${ }^{7}$ Já o argumento da "subdeterminação da teoria pelos dados" (underdetermination of theory by data) parte da ideia central de que: para qualquer teoria empiricamente adequada $\mathrm{T} 1$, pode existir outra proponente $\mathrm{T}_{2}$ também empiricamente adequada para o fenômeno em questão, porém incompatível com T1 por postular outras entidades ou apresentar o mundo de outro modo (FRENCH, 2009, p. 98; DEVITT, 2008, p. 240).

${ }^{8}$ Embora sua origem possa ser remontada ao início do século XX com o grande filósofo da semiótica

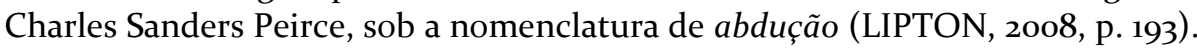


está inferindo a verdade de uma explicação para vários dados que ele deseja explicar" (HARMAN, 1965, p. 89). Contudo, como observa Silva (2011), Harman não está nos dizendo que os cientistas partem da existência das entidades inobserváveis, mas sim que elas são inferidas legitimamente, portanto a existência dos inobserváveis não é uma premissa, mas sim uma conclusão9 .

Sendo assim, partindo da passagem anterior do próprio Harman, o argumento pode ser reformulado do seguinte modo (SILVA, 2011, p. 275):

1) uma evidência $E$ deve ser explicada;

2) a hipótese $\mathrm{H}$ explica melhor $\mathrm{E}$ do que outras hipóteses rivais;

3) conclusão: $\mathrm{H}$ é passível de crença em sua verdade $e$ as entidades inobserváveis postuladas por $H$ podem ser inferidas.

O argumento da IBE foi recebido com entusiasmo pelos partidários do realismo científico por volta da década de 1970, pois para eles IBE pode ser tanto um argumento persuasivo quanto por cumprir três papéis fundamentais dentro da proposta realista: 1) IBE legitima filosoficamente o realismo científico perante suas alternativas rivais se for tomado como um meta-argumento, isto do seguinte modo: "a) o sucesso da ciência deve ser explicado; b) o realismo explica melhor este sucesso do que outras hipóteses rivais; c) conclusão: o realismo é verdadeiro" (SILVA, 2011, p. 275); 2) Oferece uma explicação da inferência de entidades inobserváveis como resultados de um "complexo processo argumentativo e não de uma precipitação ontológica" (SILVA, 2011, p. 275); 3) IBE se apresenta como uma descrição fidedigna do processo científico real.

\section{2 - A clássica objeção do argumento do Conjunto Defeituoso}

IBE não foi poupada de críticas pelos antirrealistas, sobretudo quanto ao que é afirmado na segunda premissa do argumento, pois ela exprime um caráter eliminativo para a produção e aceitação de hipóteses que seria operado pelo cientista de forma imparcial, baseando-se em seu conhecimento de fundo, buscando eliminar hipóteses teóricas rivais e optando pela que mais se adequa à resolução do problema em questão, garantindo deste modo a confiabilidade da teoria vigente.

\footnotetext{
${ }^{9}$ John Locke, mesmo sendo um empirista, adotou posição semelhante em relação ao significado cognitivo da ciência e a postulação de uma metafísica atomista. Para ele, os objetos externos existem independentemente da nossa consciência e o são por sua constituição atômica, que pode ser inferida partindo da experiência e deduzindo por analogia. No entanto, isso violaria uma das regras do empirismo sob a ótica de van Fraassen, pois isso não seria garantia de uma seguridade na crença real de entidades inobserváveis; sendo assim, Locke estaria mais próximo de uma noção realista ao invés de empirista (antirrealista), no que tange somente ao debate realismo/antirrealismo. (SILVA, 2007, p. 61).
} 
Uma crítica contundente foi elaborada por um dos filósofos antirrealistas mais famosos e também formulador do Empirismo Construtivo ${ }^{10}$, Bas van Fraassen, com o assim denominado Argumento do Conjunto Defeituoso (Bad Lot) contido na obra Lawsand Symmetry (1989) ". Basicamente van Fraassen levanta a seguinte tese: suponhamos que dentro de uma disputa científica temos uma série de teorias rivais, tais como $\mathrm{T}_{1}, \mathrm{~T}_{2}, \mathrm{~T}_{3}$ e $\mathrm{T}_{4}$, que buscam explicar determinado fenômeno $\mathrm{Y}$, e no meio desta disputa vamos também supor que se evidenciou por algum critério de seleção justificado que a teoria $\mathrm{T}_{3}$ explica o fenômeno $\mathrm{Y}$ melhor que as demais proponentes; sendo assim, de acordo com a IBE o realista afirma a verdade da teoria $\mathrm{T}_{3}$, bem como as entidades postuladas por ela. Então van Fraassen questiona: e se nós estávamos diante de um conjunto de teorias defeituoso? Ou seja, o que nos garante que dentre as teorias do conjunto analisado ( $\mathrm{T}_{1}, \mathrm{~T}_{2}, \mathrm{~T}_{3}$ e $\left.\mathrm{T}_{4}\right)$ se encontra aquela que corresponde objetivamente ao fenômeno em questão e não há a possibilidade de ser uma teoria até não formulada?

Permanece sempre possível que a verdade esteja entre outras teorias que ninguém tenha considerado, e não existe forma de julgar o quão provável isto seja. A conclusão do argumento é a de que, a despeito de a melhor das teorias produzidas poder ser verdadeira, os cientistas nunca possuem boas razões para acreditar nisto. Eles sabem qual das teorias rivais que eles testaram provavelmente seja a verdadeira, mas eles não sabem como julgar a probabilidade de que qualquer destas teorias o seja. (LIPTON, 2010, p. 314).

Tal argumento se mostrou como uma relevante crítica tanto à IBE quanto ao Realismo, o que veio a provocar uma série de respostas por parte dos realistas nos anos que sucederam sua publicação, conforme indicaremos na próxima seção.

\section{3 - Réplicas ao Bad Lot}

Dentre as respostas por parte dos realistas ao argumento de van Fraassen, podemos ressaltar a objeção clássica proposta por Peter Lipton (1993, p. 92), Stathis Psillos (200o, p. 51-52) e Michel Devitt (1997, p. 143) de que existem duas opções da conclusão de IBE, uma realista e outra empirista; logo, as mesmas objeções levantadas contra a conclusão realista de que as teorias são verdadeiras, são aplicadas também à conclusão empirista-construtiva de que as teorias são empiricamente adequadas; portanto não há garantias epistemológicas da crença de que estamos diante da melhor adequação empírica possível.

\footnotetext{
${ }^{10}$ Empirismo Construtivo é a proposta lançada por van Fraassen em 1980 com sua obra The Scientific Image, como uma alternativa ao Realismo Científico. Nesta concepção filosófica, nossas melhores teorias científicas podem ser verdadeiras ou aproximadamente verdadeiras ao que tange o mundo observável, desde que sejam empiricamente adequadas; já no domínio do inobservável elas podem nos dizer como o mundo é, porém nunca seremos capazes de inferir a validade epistêmica de uma entidade inobservável (VAN FRAASSEN, 2007, p. 33-34).

${ }^{11}$ Embora um anúncio do argumento já possa ser encontrado na obra The Scientific Image (1980) (SILVA; MINIKOSKI, 2016, p. 243-4).
} 
Van Fraassen, junto a colaboradores (James Ladyman, Igor Douven e Leon Horsten), publicou uma réplica em 1997 esclarecendo alguns pontos errôneos de tal perspectiva, sobretudo da crítica de Psillos. Em suma, os equívocos dos realistas assentam-se num erro de interpretação do que é a adequação empírica proposta pelo Empirismo Construtivo ${ }^{12}$, pois ela não está em pé de igualdade com a visão realista de verdade das teorias. O realismo propõe que as teorias científicas nos forneçam "um relato literalmente verdadeiro de como o mundo é" (VAN FRAASSEN, 200o, p. 11), o que é completamente diverso de assumir como pressuposto que a ciência somente nos forneça "teorias que são empiricamente adequadas" (VAN FRAASSEN [1997], 2000, p. 11). De fato, van Fraassen nunca alegou que a adequação empírica (absoluta) esteja acessível à ciência, da mesma forma que nunca negou essa possibilidade. No mais, não é necessária uma relação entre o Argumento do Conjunto Defeituoso e o Empirismo Construtivo, pois tal argumento poderia ser levantado mesmo sem a formulação desta concepção filosófica.

Superadas as primeiras críticas, devemos relembrar que van Fraassen em seu argumento afirma que embora possamos acreditar que IBE oferece uma seleção correta entre as hipóteses, o único modo de sabermos que não estamos diante de um conjunto defeituoso seria assumirmos o princípio de sermos "naturalmente predispostos pela natureza a nos depararmos com uma série correta de hipóteses" (VAN FRAASSEN, 1989), porém este princípio não possui suporte racional para van Fraaseen. Stathis Psillos buscou responder tal ponto, alegando que o argumento de van Fraassen se limita somente ao aspecto lógico e abstrato, não possuindo relação com a prática científica real e, para tanto buscou mostrar categoricamente que o

\footnotetext{
${ }^{12}$ Van Fraassen define o conceito de 'adequação empírica' em dois momentos de The Scientific Image: (1) "Por ora, vamos ficar com a explicação preliminar de que uma teoria é empiricamente adequada exatamente se o que ela diz sobre as coisas observáveis e eventos neste mundo são verdadeiros exatamente se ela 'salva os fenômenos'. De forma um pouco mais precisa: tal teoria tem, pelo menos, um modelo tal que todos os fenômenos dados nele se ajustam (p. 12)"; e (2) "Apresentar uma teoria é especificar uma família de estruturas, seus modelos; e, em segundo lugar, especificar certas partes desses modelos (as subestruturas empíricas) como candidatas à representação direta dos fenômenos observáveis. As estruturas que podem ser descritas em relatos experimentais e de medição podemos chamar de aparências; a teoria é empiricamente adequada se possui algum modelo tal que todas as aparências sejam isomórficas a subestrutura empírica daquele modelo (p. 64)". O filósofo representa aqui as duas dimensões da adequação empírica: a) seu aspecto semântico, por compreender a teoria como um conjunto de modelos; b) sua dimensão empirista, por manter as exigências epistêmicas do empirismo ao relacionar que os modelos pretendem ser representantes diretos dos fenômenos observáveis (subestrutura empírica). Uma teoria 'salva um fenômeno' observável, se um de seus modelos é isomórfico aos relatos experimentais e de medição (aparências). No entanto, não devemos entender o uso do termo 'isomorfismo' com a noção de verdade por correspondência para a adequação; pois aqui ele é aplicado num sentido 'geométrico', referindo-se ao encaixe que ocorre entre modelos diferentes e subestruturas de um mesmo modelo (igualdade de formas). Tais modelos seriam: (1) Superestrutura empírica: uma estrutura geral que compreende todas as famílias de modelos da teoria científica; (2) Subestrutura empírica: conjunto de modelos (teóricos) que buscam representar as aparências; (3) Aparências: conjunto de modelos de fenômenos, toda a família de dados construída a partir de medições experimentais. A adequação empírica ocorre quando há isomorfismo entre dois dos três modelos da estrutura geral, a saber: entre a subestrutura empírica e os modelos de aparências.
} 
"privilégio" exigido por van Fraassen realmente existe e pode ser denominado de "privilégio do conhecimento anterior" (PSILLOS, 2000).

Psillos afirma que o privilégio do conhecimento anterior consolidado tem duas dimensões: 1) ele limita o espaço das hipóteses alternativas que podem fornecer uma possível explicação para a evidência disponível; 2) quando o conhecimento anterior sugere mais de uma hipótese teórica para a evidência em questão, as considerações explicativas da prática científica selecionam a melhor das alternativas.

\section{Considerações finais}

O que se observa diante das críticas apresentada acima, é que os realistas reivindicam a natureza epistemológica de IBE como um argumento consistente dado sua relação com a prática científica, pois graças ao conceito de conhecimento anterior estabelecido, podemos ter seguridade nas crenças de nossas melhores teorias, ao passo que o argumento de van Fraassen não é mais do que uma objeção lógica e abstrata sem relação com a realidade da prática científica.

Contudo, embora o conceito de conhecimento anterior seja muito utilizado na literatura corrente do debate pelos realistas científicos, buscando estabelecer uma relação pragmática de seguridade epistêmica com a prática inferencial dos cientistas, tal ponto jamais foi devidamente explorado pelos mesmos, evidenciando como se dá a construção e consolidação desse mesmo conhecimento para validar os argumentos que recorrem ao conceito. Para tanto, seria necessário fazer uso de uma sociologia e filosofia da ciência que considerassem os aspectos sociais e institucionais envolvidos na real prática científica dentro dos laboratórios, mas sem desconsiderar o valor epistêmico das teorias ou simplesmente separá-lo dos outros aspectos vinculados, tal como a proposta socioconstrutivista do autor francês Bruno Latour.

Seguramente, podemos afirmar que o argumento do Bad Lot de van Fraassen continua se mostrando como uma pungente crítica à IBE e ao Realismo Científico, este que não pôde descartá-lo através das críticas de seus adeptos, muito embora a réplica de Psillos tenha se mostrado como uma importante objeção à aplicação real da tese de van Fraassen, por se utilizar do conceito de conhecimento anterior consolidado. No entanto, Psillos (ou outro realista) jamais clarificou como se dá o desenvolvimento do conhecimento anterior e se ele realmente pode conceder uma seguridade epistêmica à prática inferencial do cientista, validando assim o realismo científico e seu conceito de verdade (aproximada). O único modo de investigar tal conceito e sua aplicação seria através de uma análise sociológica da prática científica a fim de compreender a produção de modalidades, levando em consideração todos os aspectos sociais como determinantes para o resultado final que o cientista alcança e lega à comunidade. 
Concluímos deste modo que um estudo aprofundado da construção, consolidação e aceitação do conhecimento anterior é fundamental para uma justa análise do argumento de van Fraassen e sua relação com a prática científica, portanto, tal estudo é de suma importância também para o debate realismo/antirrealismo científicos. O desafio que se apresenta, é uma investigação acerca da relação do conceito de conhecimento de fundo com a prática científica, e, uma proposta que sugerimos para a continuidade deste programa de pesquisa é valer-se do socioconstrutivismo do antropólogo, sociólogo e filósofo da ciência francês, Bruno Latour. De acordo com Latour, partindo de sua obra Ciência em Ação (1987), a produção de hipóteses alternativas pode ser muito complexa e geralmente inúmeras vezes não há a produção de hipóteses rivais por parte dos cientistas na constituição do conhecimento anterior e na seleção de uma possível melhor teoria. Portanto, uma análise da prática científica à luz de seu socioconstrutivismo pode ser uma contribuição relevante para a questão entre van Fraassen e os realistas, ao menos no que tange à problemática da seleção de hipóteses científicas rivais e o valor epistêmico atribuído.

\section{Referências}

BERKELEY, G. De motu. Tradução: Marcos Rodrigues da Silva. In Scientiae Studia. v. 4, n. 1. BIRD, A. Inferência da única explicação. Tradução: Marcos Rodrigues da Silva. In Cognitio, 15(2): 375-384, 2014.

BUENO, O. O empirismo construtivo: uma reformulação e defesa.Campinas, SP: Unicamp, 1999.

CURD, M.; PSILLOS, S. (org. - 2014) - The routledge companion to philosophy of science. Abingdon-Oxon: Routledge.

FRENCH, S. Ciência: conceitos-chave em filosofia. Tradução André Klaudat. Porto Alegre: Artmed, 2009.

FUMERTON, R. Induction and reasoning to the best explanation. In: Philosophy of Science, 47, 1980 .

GHINS, M. Uma introdução à metafísica da natureza: Representação, realismo e leis científicas. Tradução: Eduardo Salles O. Barra; Ronei Clécio Mocellin. Curitiba: Ed. UFPR, 2013.

HARMAN, G. The inference to the best explanation. In Philosophical Review, 74 88-95 (1968).

LAUDAN, L.A confutation of convergent realism. In Philosophy of Science, Vol. 48, No. 1 (Mar., 1981), pp. 19-49.

. O progresso e seus problemas. Tradução: Roberto Leal Ferreira. São Paulo: Ed. UNESP, 2010.

NEWTON-SMITH, W. Berkeley's philosophy of science. In Essays on Berkeley (ed. Foster, J. \& Robinson, H.). Oxford: Clarendon Press. Philosophy 14. (1985).

OKASHA, S. Philosophy of science: a very short introduction. Oxford: Oxford University Press, 2002. 
PSILLOS, S. Scientific realism: how science tracks truth. London: Routledge, 1999.

. Sobre a crítica de van Fraassen ao raciocínio abdutivo. Tradução: Marcos Rodrigues da Silva; Alexandrer Meyer. In Revista Crítica. Londrina: UEL, 2000.

PUTNAM, H.; PERUZZO, L. Interview: mind, body and world in the philosophy of Hilary Putnam. In Trans/Form/Ação v. 38, n. 2, Marília: 2015.

SILVA, M. Instrumentalismo e explicação científica no de motu de Berkeley. In Scientiae Studia vol. 4, n. 1 (2006).

SILVA, M.; CASTILHO, D. Inferências eliminativas e o problema das alternativas não concebidas. In Filosofia Unisinos v. 16.

SILVA, M.; MINIKOSKI, D. Van Fraassen e a inferência da melhor explicação. In Problemata: R. Intern. Fil. v. 7. n. 1 (2016).

SILVA, M. O problema da aceitação de teorias e a inferência da melhor explicação. In Cognitio v. 12, n. 2011.

SOUZA, E. Um estudo do argumento do milagre na defesa do realismo científico. 218 p. Doutorado em Filosofia. Universidade de São Paulo, São Paulo, 2009.

VAN FRAASSEN, B. A imagem científica. Tradução Luiz Henrique de Araújo Dutra. São Paulo: Ed. UNESP, 2007. Laws and symmetry. Oxford: Oxford University Press, 1989.

Submissão: 10.10.2018 / Aceite: 20.09.2019. 